\title{
Giving control to patients
}

The editorial 'Confidentiality and Connecting for Health" asked GPs to support a campaign to encourage patients to opt-out of the NHS Care Record Service. That editorial contained a number of factual errors and wrongly conflated aspects of the National Programme for IT with existing systems and their controls. In this editorial we aim to set out the current situation of the Summary Care Record (SCR) and describe the strong control that patients are able to exercise over use of the content and use of their health information. We also aim to address any misconceptions that may have been generated.

The primary purpose of the SCR is to improve patient care by ensuring that limited but important clinical information is available in circumstances where the full records are not available. Having a summary set of information in these circumstances ensures a patient's care is not prejudiced because key information is inaccessible in a 'digital island' elsewhere within the health service. It is expected that this will be of most use in emergency departments and out-of-hours services. In addition, we expect that many patients will elect to have access to their own records and contribute personal health information through the confidential and secure website Healthspace (www.healthspace.nhs.uk). This allows patients to check the accuracy of the information held and truly makes patients partners in their own health care. As with everything in the SCR, accessing it is entirely optional for the patients.

NHS Connecting for Health is committed to making real the concept of an SCR managed by patients jointly with GPs. That is why patients have several choices about what happens to their records.

Firstly, patients can choose not to have an SCR. The SCR is only there to benefit patients themselves and it is entirely their choice whether or not to have one. In making that choice, it is essential that they are able to base it on accurate information about the benefits and risks. It is wrong for GPs not to offer patients the option to create an SCR or to put the case to them for opting out using misleading information.
Secondly, patients can have a record but choose not to share it unless they give explicit permission to each healthcare worker on each occasion. If they choose this option, they can also see it themselves via Healthspace.

Lastly, patients can choose to have an SCR which is shared with authorised users and subject to various access controls.

It is important to stress that for the first time, a greater degree of control of their records sits with patients themselves - not their GP and certainly not with NHS Connecting for Health. To ensure that the patients' wishes are complied with, rolebased access controls and legitimate relationships apply before healthcare workers can access any clinical information. ${ }^{2}$

The last decade saw the clinical governance bar raised as all parts of the health service systematically sought to improve the care it provided through audit. This decade sees the information governance challenge for the health service. We will be working in a continuously-audited environment; not only in respect to financial and clinical matters but also relating to performance in information governance. NHS Connecting for Health is providing Caldicott Guardians and privacy officers with the tools they need to audit the environment they quality assure.

NHS Connecting for Health has five early adopter sites. Over the last year, colleagues in Bolton, Bury, South Birmingham, Dorset, and Bradford and Airedale have started the first stages in creating SCRs for patients. Currently there are over 150000 live patient summaries. The process starts with a letter to every adult patient that begins a consultation period - a minimum of 16 weeks - before any summary record is created. Patients who have concerns about any aspect of the scheme can get more information in writing, by telephone through a dedicated NHS Direct line, or in person at local advice centres.

Should any patient decide not to have an SCR, they can sign a form to this effect and information on this decision will then be coded into their record, thereby ensuring that no clinical information will leave the local
GP surgery system to populate the SCR. ${ }^{3}$

If a patient chooses to have an SCR, currently the only data uploaded to the 'spine' are their current medications, allergies, and adverse reactions. Following the upload of this core data, patients can agree with their GP to enable a richer summary to be sent up to the SCR, based on the practice's local summary. Guidance for the content of the richer data set has been formulated by the RCGP. ${ }^{4}$ The GP can edit what is sent and where appropriate can withhold history items. Currently, only practices which have passed the data accreditation part of the Information Management and Technology Directed Enhanced Service for data quality and are paper light are allowed to send data to the patient's summary care record.

The early adopter experience for patients and clinicians, the implementation of the access controls, and the data quality requirement are being evaluated independently by a team led by Professor Greenhalgh from the Department of General Practice at UCL. The report is expected in late spring 2008 and will be used to modify plans as required.

At this stage, in the five early adopter sites, it appears that when patients are informed about their options, fewer than $1 \%$ are choosing not to have an SCR stored on the spine. This is similar to the opt-out rate in Scotland and Hampshire, where forms of electronic summary health records have been around for longer.

As Anderson points out, ${ }^{1}$ there is nothing new about there being NHS-wide 'databases' - whether previously in paper form or now electronic. NHS Connecting For Health currently maintains multiple databases including demographics, commissioning, screening registers, and prescriptions. The NHS could not function without this collection of critical information and the NHS determines their 'rules'. There are obligations on public health and communicable disease control structures to collect information to allow regional and local planning and disease surveillance. The ability to improve public health through access to better health information is one of 
the principle benefits of the National Programme for IT.

The SCR is one national database, but one that is entirely centred on the needs and choices of individual patients. It is an option that patients may wish to take up to ensure that the clinicians caring for them have the information needed to make safe clinical decisions. It is a health record and there will be no access for police, immigration authorities, or others. As doctors we would not be involved if such access was considered. The rules on the disclosure of copies of clinical information, for example by court order, are unchanged regardless of how the information is held. The principles and standards for the sharing and utilisation of electronic records are set out clearly in the Care Record Guarantee. ${ }^{5}$

It is on this basis that NHS Connecting for Health systems are designed and built; the challenge for the NHS is to use the controls they are provided with professionally.

\section{Mark Davies}

National Clinical Director, NHS Connecting for Health

\section{Simon Eccles}

National Clinical Director,

NHS Connecting for Health

\section{Gillian Braunold}

Clinical Director, SCR and Healthspace

\section{Marlene Winfield}

National Patient Lead, NHS Connecting for Health

\section{Michael Thick}

Chief Clinical Officer, NHS Connecting for Health

\section{REFERENCES}

1. Anderson R. Confidentiality and Connecting for Health. Br J Gen Pract 2008; 58: 75-76.
2. NHS Connecting for Health. Patient choices. www.connectingforhealth.nhs.uk/systemsandservices/inf ogov/confidentiality/choices?searchterm=access+control $s$ (accessed 8 Feb 2008).

3. NHS Connecting for Health. Guidance for managing requests for no Summary Care Record during the period of the early adopter programme.

http://www.nhscarerecords.nhs.uk/nhs/publications/gpg uidance.pdf (accessed 8 Feb 2008).

4. Royal College of General Practitioners. http://www.connectingforhealth.nhs.uk/systemsandservi ces/crs/scr (accessed 11 Feb 2008).

5. NHS Connecting for Health. The Care Record Guarantee Our guarantee for NHS care records in England. www.connectingforhealth.nhs.uk/nigb/crsguarantee/crs guarantee.pdf (accessed 8 Feb 2008)

DOI: 10.3399/bjgp08X277230

\section{ADDRESS FOR CORRESPONDENCE}

\section{Mark Davies}

National Clinical Director,

NHS Connecting for Health,

New Kings Beam House, 22 Upper Ground,

London SE1 9BW.

E-mail:markdavies@nhs.net

\section{Community-based maternity care in 2008}

Four papers published in this issue of the journal examine community-based maternity care, a topic that was also scrutinised in the recently-published Maternity Review by the Healthcare Commission, ${ }^{1}$ and the Confidential Enquiry into Maternal and Child Health report Saving Mothers' Lives. ${ }^{2}$ These reports are not comfortable reading for those concerned with the quality of maternity care.

Providing good quality maternity care has three essential elements. First is the careful balancing act needed to work with childbearing women, enabling them to be as healthy and as normal as possible, while also making sure that all potential problems are detected and appropriately addressed. Second is the effective communication needed between the range of community and hospital-based professionals involved. Third is to make sure that families have all the information and support needed at this demanding time. Straightforward as these elements may sound, different professional groups, based in different sectors, and often with different perspectives and priorities, need to work in harmony to deliver them; this is where many of the problems lie. ${ }^{3}$
The overall direction of maternity services policy has been relatively consistent since the 1993 Department of Health report Changing Childbirth. ${ }^{4}$ The majority of care for women experiencing normal pregnancy now takes place in the community - a significant shift from the over-crowded hospital antenatal clinics of the 1970s and 1980s. Women-focused and family-centred care that meets the diverse needs of women in different communities is an important goal; midwifery-led care, continuity of care, and team working by health and related professionals continue to be policy priorities. ${ }^{5,6}$ Home birth and birth in midwiferyled units are seen as appropriate choices for women with uncomplicated pregnancies. ${ }^{6-8}$ The fundamental contribution that maternity care can make to addressing inequalities in health is widely acknowledged. ${ }^{8,9}$

Other policy changes have had an impact, but not always positive. Changes in the wider NHS have contributed to a serious understaffing of community midwifery services in some parts of the country. ${ }^{10}$ Increased awareness of the complexity of women's social and health status, and the introduction of more routine antenatal screening, have led to an increase in workload that has not been met by increased capacity. Health visiting is undergoing another fundamental examination of its role and purpose, ${ }^{11}$ which is likely to have an impact on health visitors' involvement in maternity care. The reorganisation of out-ofhours GP services has contributed to limiting GPs' involvement in intrapartum care even further. Sure Start programmes and Children's Centres, established to offer local services to the most vulnerable families, have caused a major reorganisation of community-based care, and these services are likely to develop further. ${ }^{12}$

A coordinated response to maternity service policy challenges is lacking, as demonstrated by the papers in this issue of the journal, ${ }^{13-15}$ and other sources: pregnant women still routinely attend first to their GP before being referred to the midwife, ${ }^{1}$ continuing the duplication of early pregnancy care services despite the rhetoric of midwifery-led care. We are still however, reading about the neglect of mental health issues, despite the evidence of its' 